\title{
Factors Governing the Host-Guest Interactions between IIA/IIB Group Metal Cations and $\alpha$-Cyclodextrin: A DFT/CDM Study
}

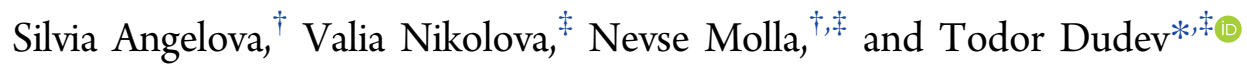 \\ ${ }^{\dagger}$ Institute of Organic Chemistry with Centre of Phytochemistry, Bulgarian Academy of Sciences, 1113 Sofia, Bulgaria \\ ${ }^{\ddagger}$ Faculty of Chemistry and Pharmacy, Sofia University "St. Kl. Ohridski”, 1164 Sofia, Bulgaria
}

\section{Supporting Information}

ABSTRACT: Cyclodextrins' unique molecular structure with hydrophilic exterior surface and nonpolar cavity interior is responsible for their specific complexation properties. Although a wealth of information about these molecules has been accumulated, many aspects of their coordination chemistry remain unknown. For example, there are no systematic studies on the key factors controlling the processes of metal binding and selectivity in these systems. In the computational study herein, DFT molecular modeling has been employed to study the interactions of either hydrated or nonhydrated IIA/IIB group metal cations $\left(\mathrm{Be}^{2+}, \mathrm{Mg}^{2+}, \mathrm{Ca}^{2+}, \mathrm{Sr}^{2+}, \mathrm{Ba}^{2+}\right.$, $\left.\mathrm{Zn}^{2+}, \mathrm{Cd}^{2+}, \mathrm{Hg}^{2+}\right)$ with the host $\alpha$-cyclodextrin molecules. The thermodynamic descriptors (Gibbs free energies in the gas phase and in water medium) of the metal binding to $\alpha$-cyclodextrin have been evaluated, and the effect of various factors (metal's radius, electron configuration and coordination number, and host molecule flexibility and binding site locality) on the interactions between the two binding partners has been assessed. The results obtained shed light on the intimate mechanism of the metal binding to $\alpha$-cyclodextrin and disclose the key factors governing the process.

\section{INTRODUCTION}

Cyclodextrins (CDs) are "circular polymers" of $\alpha$-D-glucopyranoside units that have been known to science and industry for over 100 years. ${ }^{1,2}$ They typically contain six, seven, or eight glucose units in the ring, each structure being referred to as $\alpha$-, $\beta$-, and $\gamma$-cyclodextrin, respectively. ${ }^{3}$ What makes these molecules interesting is their shape, described as a doughnut or wreath-shaped truncated cone. The second important feature is that the walls of the cyclodextrins are hydrophobic, but the two rims (upper/narrow and lower/wide rim), which are trimmed with $\mathrm{OH}$ groups (primary and secondary $\mathrm{OH}$ groups, respectively), are hydrophilic. As a result, the exterior of these unusual molecules is hydrophilic, and the cavity is hydrophobic, which gives cyclodextrins the ability to accommodate hydrophobic molecules/moieties (solid, liquid, and gaseous compounds) inside its cavity. ${ }^{2,4,5}$ This special feature of cyclodextrins accounts for a variety of beneficial effects and diverse applications in many areas (e.g., supramolecular chemistry, catalysis, drug carrier systems, food industry, and cosmetics) and industrial production on the thousands-of-tons scale. $^{6-15}$ Notably, CDs can be considered as simple artificial biomimetic ion channels ${ }^{16}$ and enzyme models; ${ }^{9,17,18}$ hence, elucidating the mechanism of their complexation with metals/ organic molecules is of particular interest.

The CDs inclusion complexes with guest molecules found in the literature are thousands. Strangely, the focus has been laid almost exclusively on the complexation properties of CDs toward organic inclusates, whereas the use of metal ions as guest entities to the $\mathrm{CD}$ host has attaracted little attention, thus yielding a limited number of papers on the subject. Cai et al. have shown via ES-MS and ES-MS/MS experiments, as well as by theoretical calculations, that iron(II) and magnesium(II) cations act as agents for stabilizing noncovalent complexes of cyclodextrin and neutral aromatic molecule (toluene) in the gas phase. ${ }^{19}$ Mass spectrometric fragmentation pathways of $\beta$ cyclodextrin cationized by divalent metals have been reported. ${ }^{20}$ The authors have demonstrated that the $\mathrm{M}^{2+}$ / $\beta \mathrm{CD}(\mathrm{M}=\mathrm{Fe}, \mathrm{Co}, \mathrm{Cu}, \mathrm{Ni}, \mathrm{Zn})$ has catalytic properties in an asymmetric aldol condensation reaction due to the presence of metal dications in the complex. ${ }^{21}$ Furthermore, metal cations have been used as a third component in the so-called "ternary cyclodextrin complexes", drug/CD/metal constructs where the presence of metal species improves drug solubility. ${ }^{22}$ For example, $\mathrm{Mg}^{2+}$ ions have been employed in doxycycline solubilization in aqueous solution containing 2-hydroxypropyl- $\beta$-cyclodextrin $(\mathrm{HP} \beta \mathrm{CD}){ }^{23}$ Also, the interactions between the $\beta$-cyclodextrin ligand and bare $\mathrm{Na}^{+}, \mathrm{Cu}^{+}, \mathrm{Mg}^{2+}, \mathrm{Zn}^{2+}$, and $\mathrm{Al}^{3+}$ cations have been investigated in detail using density functional theory modeling at the B3LYP/6-31G* level. ${ }^{24}$ The calculations have provided information about the structure of the host-guest complexes and the locality of the metal binding site as well.

Received: October 21, 2016

Published: January 30, 2017 
Although a considerable amount of information about the complexation properties of cyclodextrins has been accumulated, many aspects of their coordination chemistry remain unknown. For example, there are no systematic studies on the key factors controlling the processes of metal binding and selectivity in these systems. Notably, information about metal ligation properties of the smallest member of the cyclodextrin family, $\alpha$-cyclodextrin ( $\alpha \mathrm{CD})$, is still lacking (to the best of our knowledge). A number of questions wait to be answered: (1) To what extent do the properties of the metal cation influence the metal-cyclodextrin recognition process? (2) Which structural zone of the cyclodextrin host does exhibit the greatest affinity for the metal guest? (3) How do the dielectric properties of the environment affect the processes of metal binding and selectivity in these systems? (4) Cyclodextrin can act as a ligand of the first or second coordination sphere of the metal cation. Which of these coordination modes does favor to a greater degree the complexation process in the host-guest system?

Here, by employing density functional theory (DFT) calculations combined with continuum dielectric method (CDM) computations, we endeavor to answer these questions by evaluating the thermodynamic descriptors of the IIA/IIB group metal binding to $\alpha \mathrm{CD}$ and assessing how the interaction between the two binding partners depends on (1) the size, electron configuration, and hydration state of the guest metal cation, (2) flexibility of the host molecule, (3) dielectric properties of the environment, and (4) the locality of the binding site. Group IIA and IIB metal cations have been chosen for the task as their complexation properties are of special interest to analytical chemistry, environmental chemistry, and biochemistry. The results obtained shed light on the intimate mechanism of metal binding to $\alpha \mathrm{CD}$ and disclose the key factors governing the process.

\section{COMPUTATIONAL DETAILS}

The M062X functional ${ }^{25}$ was used in the geometry optimization of $\alpha \mathrm{CD}$ and metal complexes to evaluate the respective electronic energies, $E_{\mathrm{el}}$. This global hybrid functional has been shown to be efficient in main group thermochemistry, kinetics, and noncovalent interactions calculations. The calculations were performed with the 6$31 \mathrm{G}(\mathrm{d}, \mathrm{p})$ basis set for the lighter atoms $(\mathrm{C}, \mathrm{O}, \mathrm{H}, \mathrm{Be}, \mathrm{Mg}, \mathrm{Ca}$, and $\mathrm{Zn})$ and with SDD pseudopotential for the heavier ones $(\mathrm{Sr}, \mathrm{Ba}, \mathrm{Hg}$, and $\mathrm{Cd}$ ) using the Gaussian 09 program. ${ }^{26}$ Among several method/basis set combinations, the M062X/(6-31G(d,p); SDD) level of theory was chosen for performing the desired task as it reliably reproduces the mean metal-oxygen bond distances in complexes with ligands resembling $\alpha \mathrm{CD}$ such as sugar alcohols (erythritol) and sugars (lactose): $\mathrm{Ca}^{2+}-\mathrm{O}_{\text {erythritol }}(\exp )^{27}=2.410 \AA$ and $\mathrm{Ca}^{2+}-\mathrm{O}_{\text {erythritol }}$ (calcd) $=2.405 \AA ; \mathrm{Ca}^{2+}-\mathrm{O}_{\text {lactose }}(\exp )^{28}=2.500 \AA$ and $\mathrm{Ca}^{2+}-\mathrm{O}_{\text {lactose }}($ calcd $)=$ $2.506 \AA$ (present work, Supporting Information).

Frequency calculations for each optimized structure were performed at the same level of theory. No imaginary frequency was found for the lowest energy configurations of any of the optimized structures. The frequencies were scaled by an empirical factor of $0.979^{29}$ and used to compute the thermal energies, $E_{\mathrm{th}}$, including zero-point energy, and entropies, $S$.

The differences $\Delta E_{\mathrm{e}}, \Delta E_{\mathrm{th}}, \Delta P V$ (work term), and $\Delta S$ between the products and reactants were used to calculate the gas-phase $\Delta G^{1}$ free energy of complex formation in the gas phase at $T=298.15 \mathrm{~K}$ according to eq 1

$$
\Delta G^{1}=\Delta E_{\mathrm{el}}+\Delta E_{\mathrm{th}}+\Delta P V-T \Delta S
$$

Solvation effects were accounted for by employing the polarizable continuum model $(\mathrm{PCM})^{30}$ as implemented in the Gaussian 09 suite of programs. ${ }^{26}$ The fully optimized structure of each reactant and product in the gas phase was subjected to single point PCM calculations in water (with dielectric constant $\varepsilon=78$ ) to evaluate the respective free energies of solvation, $\Delta G_{\text {solv }}{ }^{78}$. These were used to calculate the free energy of complex formation in condensed medium (water).

$$
\Delta G^{78}=\Delta G^{1}+\Delta G_{\text {solv }}{ }^{78} \text { (products) }-\Delta G_{\text {solv }}{ }^{78} \text { (reactants) }
$$

A positive $\Delta G^{78}$ implies a thermodynamically unfavorable complex formation, whereas a negative value implies a favorable one.

The PyMOL molecular graphics system was used for generation of the molecular graphics images. ${ }^{31}$

\section{RESULTS AND DISCUSSION}

Structure of $\alpha C D$. The lowest-energy optimized structure of $\alpha \mathrm{CD}$ is shown in Figure 1 in two projections. The system is

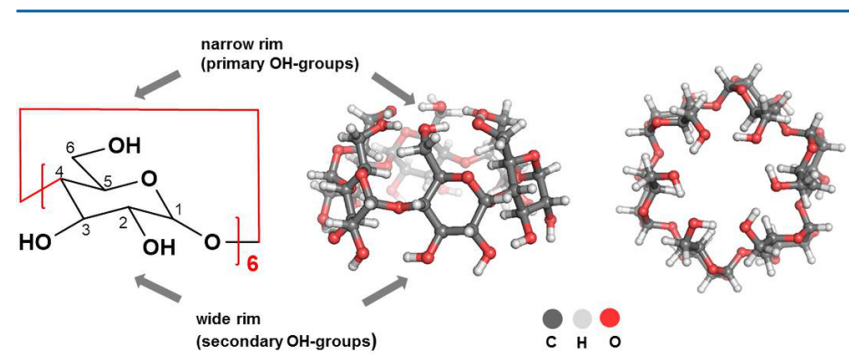

Figure 1. Molecular structure of $\alpha \mathrm{CD}$. The optimized structure is presented in two projections: side view and view from the narrow rim.

highly symmetric possessing a nearly 6-fold symmetry. The main symmetry $z$-axis is defined as the axis through the center of $\alpha$-CD and perpendicular to the mean plane of the oxygen atoms from the primary $\mathrm{OH}$ groups. These form a ring/belt of hydrogen bonds that makes the cavity practically closed from the narrow rim side. Hydrogen bonds are also formed in the wide rim, although, as judged from the respective geometrical parameters, with weaker strength than their narrow rim counterparts. The orientation of intramolecular hydrogen bonds at both rims is opposite: looking from the narrow rim side, the orientation of the wide rim hydrogen bonds is clockwise, while the orientation of the narrow rim hydrogen bonds is counterclockwise.

$\alpha C D$ as a First-Shell Ligand for IIA/IIB Group Metal Cation: $[\alpha \mathrm{CD}-\mathrm{M}]^{2+}$ Complexes. Formation of $[\alpha \mathrm{CD}-\mathrm{M}]^{2+}$ complexes $(\mathrm{M}=\mathrm{IIA} / \mathrm{IIB}$ group metal $)$ where $\alpha \mathrm{CD}$ acts as a first-shell ligand to the metal cation was studied. The initial location of the metal cation for subsequent geometry optimization of the complex was chosen after a series of preliminary partial optimizations where the metal cation was positioned either above the narrow rim or below the lower (wide) rim. The position of the metal cation was only optimized, whereas the structure of the host $\alpha \mathrm{CD}$ molecule was kept frozen. Regardless of the starting geometry, the two structures converged to a construct where the metal cation was coordinated in the plane of the hydroxyl groups from the narrow rim. Therefore, the subsequent full optimization of $[\alpha \mathrm{CD}-\mathrm{M}]^{2+}$ complexes started from geometry with the metal cation positioned at the center of the narrow rim plane. The system was allowed to fully relax upon geometry optimization. The resultant optimized structures of the respective metal complexes are shown in Figure 2. Depending on the geometrical and physicochemical characteristics of the metal cation, the final geometries of the respective complexes differ: 

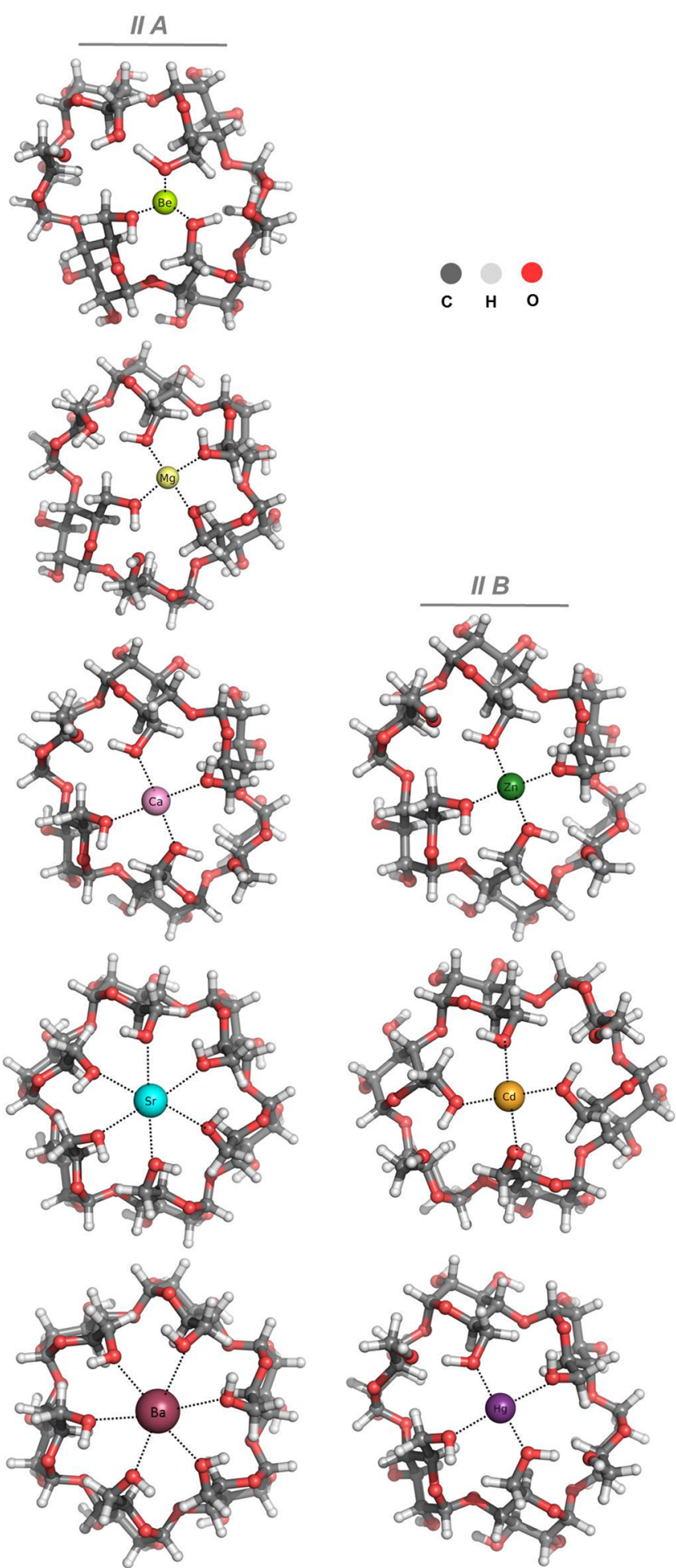

Figure 2. M062X/6-31G $(\mathrm{d}, \mathrm{p})$ fully optimized structures of $[\alpha \mathrm{CD}-$ $\mathrm{M}]^{2+}$ complexes in the gas phase.

the initial shape of truncated cone becomes distorted for all metal cations except $\mathrm{Sr}^{2+}$ and $\mathrm{Ba}^{2+}$, where the highest 6-fold symmetry is preserved.

The coordination number of $\mathrm{Be}^{2+}$ cation in the complex is equal to 3; that of $\mathrm{Mg}^{2+}, \mathrm{Ca}^{2+}, \mathrm{Zn}^{2+}, \mathrm{Cd}^{2+}$, and $\mathrm{Hg}^{2+}$ is 4; and that of $\mathrm{Sr}^{2+}$ and $\mathrm{Ba}^{2+}$ is 6 . In the $[\alpha \mathrm{CD}-\mathrm{Be}]^{2+}$ complex, the metal is bound to oxygen atoms of two adjacent $\mathrm{OH}$ groups and an oxygen from the opposite $\mathrm{OH}$ group. $\mathrm{Mg}^{2+}$ ion coordinates to three adjacent $\mathrm{O}$ atoms from the primary rim and to an oxygen atom located opposite to the triplet of the metal bound $\mathrm{OH}$ groups. $\mathrm{Ca}^{2+}, \mathrm{Zn}^{2+}, \mathrm{Cd}^{2+}$, and $\mathrm{Hg}^{2+}$ ions tend to coordinate to four oxygens grouped in two pairs. In $[\alpha \mathrm{CD}-$ $\mathrm{Sr}^{2+}$ and $[\alpha \mathrm{CD}-\mathrm{Ba}]^{2+}$ structures, containing the most bulky metal cations in the series, all of the primary $\mathrm{OH}$ groups are involved in coordinative bond formation. Note that the metal cation virtually destroys the hydrogen-bond network between the primary $\mathrm{OH}$ groups as the electron density in the metal complex is redistributed and charge transfer redirected from the narrow rim toward the metal cation (compare structures in Figures 1 and 2).

Thermodynamic parameters for the complex formation reaction $\alpha \mathrm{CD}+\mathrm{M}^{2+} \rightarrow[\alpha \mathrm{CD}-\mathrm{M}]^{2+}$ with bare metal cations are given in Table 1. Data presented reveal that the process is enthalpy driven as the entropy contributes little to the overall free energy. Furthermore, the calculations indicate that there is a rough correlation between the metal cation radius and $\Delta G$ values: the smaller is the cationic radius (and higher is the respective charge density of the cation), the more thermodynamically favorable is the complex formation in each group. These results are in line with earlier findings concerning the energetics of metal-carbohydrate complex formation demonstrating that the electrostatic interactions between the metal and ligating oxygen atoms are the dominant force governing the process. $^{33-35}$ All of the reactions in the gas phase are favorably characterized with quite large negative formation free energies. Solvation effects, however, greatly attenuate the free energy gains in the gas phase and render some reactions unfavorable in aqueous medium (positive $\Delta G^{78}$ for the $\mathrm{Sr}^{2+}, \mathrm{Ba}^{2+}, \mathrm{Cd}^{2+}$, and $\mathrm{Hg}^{2+}$ complex formation). This is due to the large desolvation penalty inflicted on the reactants in the formation process $\alpha \mathrm{CD}$ $+\mathrm{M}^{2+} \rightarrow[\alpha \mathrm{CD}-\mathrm{M}]^{2+}$, which greatly exceeds the free energy gain on solvating the metal complex, thus significantly attenuating the resultant free energy in solution, $\Delta G^{78}$. For example, applying eq 2 for the $\alpha \mathrm{CD}+\mathrm{Mg}^{2+} \rightarrow[\alpha \mathrm{CD}-\mathrm{Mg}]^{2+}$ reaction yields $\Delta G^{78}=-293.8-152.5+(18.8+394.6)=$ $-32.9 \mathrm{kcal} / \mathrm{mol}$ (Table 1 ).

In comparing the magnitude of $\Delta E_{\mathrm{el}} / \Delta G$ between IIA and IIB subgroups, the role of charge-accepting ability of the guest cation in complex formation stands out. Cations from the IIB group, due to favorable hybridization between the valence sorbital and highest occupied d-orbitals resulting in low-lying electron-receptive orbitals, are better electron density acceptors than their counterparts from the IIA group with similar ionic radii (Table 2). Thus, between $\mathrm{Zn}^{2+}$ and $\mathrm{Mg}^{2+}$, two cations with virtually identical ionic radii ( 0.74 and $0.72 \AA$, respectively), the complexes of the former (with charge transfer to the metal of $0.483 \mathrm{e}$ ) are more stable characterized by lower $\Delta E_{\mathrm{el}} / \Delta G$ $(-353 /-341 \mathrm{kcal} / \mathrm{mol})$ than those of the latter $(-306 /-294$ $\mathrm{kcal} / \mathrm{mol}$; charge transfer to the metal of $0.386 \mathrm{e})$. The same trend holds for $\mathrm{Cd}^{2+}$ and $\mathrm{Ca}^{2+}$, and $\mathrm{Hg}^{2+}$ and $\mathrm{Sr}^{2+}$ as well. Both the size and the charge-accepting properties of the metal cation appear to be major determinants of metal selectivity in this system: $\alpha \mathrm{CD}$ preferentially binds smaller cations with enhanced charge-accepting abilities.

As discussed above, the host $\alpha \mathrm{CD}$ molecule undergoes substantial geometrical distortions upon metal binding. To what extent does $\alpha \mathrm{CD}$ flexibility contribute to the energetics of $[\alpha \mathrm{CD}-\mathrm{M}]^{2+}$ complex formation? To answer this question, we performed partial geometry optimizations of the metal-loaded $\alpha \mathrm{CD}$ complexes where the metal cation was placed at the center of the narrow rim plane of the undistorted host molecule, and the structure of the $\alpha \mathrm{CD}$ host was kept frozen. 
Table 1. Ionic Radii of Metal Cations $(\AA)$ and Thermodynamic Parameters (in kcal/mol) in the Gas Phase (Superscript 1 ) and Water Environment (Superscript 78) Calculated for the Metal Complex Formation Reaction, $\alpha \mathrm{CD}+\mathrm{M}^{2+} \rightarrow[\alpha \mathrm{CD}-\mathrm{M}]^{2+}$

\begin{tabular}{|c|c|c|c|c|c|c|c|c|}
\hline \multirow[b]{2}{*}{ metal cation } & \multirow[b]{2}{*}{ ionic radius $^{a}$} & \multicolumn{5}{|c|}{ full optimization } & \multicolumn{2}{|c|}{ partial optimization } \\
\hline & & $\Delta E_{\mathrm{el}}{ }^{1}$ & $\Delta H^{1}$ & $T \Delta S^{1}$ & $\Delta G^{1}$ & $\Delta G^{78}$ & $\Delta E_{\mathrm{el}}{ }^{1}$ & $\Delta G^{1}$ \\
\hline $\mathrm{Be}^{2+}$ & 0.27 & -446.9 & -447.3 & -12.5 & -434.8 & -119.6 & -286.8 & -274.7 \\
\hline $\mathrm{Mg}^{2+}$ & 0.72 & -306.0 & -306.1 & -12.3 & -293.8 & -32.9 & -211.0 & -198.8 \\
\hline $\mathrm{Ca}^{2+}$ & 1.00 & -226.0 & -226.7 & -9.7 & -217.0 & -9.4 & -182.2 & -173.2 \\
\hline $\mathrm{Sr}^{2+}$ & 1.18 & -183.8 & -182.5 & -12.2 & -170.3 & 13.4 & -156.6 & -143.1 \\
\hline $\mathrm{Ba}^{2+}$ & 1.35 & -165.7 & -165.0 & -11.7 & -153.3 & 22.8 & -137.0 & -124.5 \\
\hline $\mathrm{Zn}^{2+}$ & 0.74 & -353.3 & -353.4 & -12.7 & -340.8 & -44.8 & -237.9 & -225.4 \\
\hline $\mathrm{Cd}^{2+}$ & 0.95 & -277.4 & -277.9 & -11.4 & -266.6 & 13.0 & -204.4 & -193.5 \\
\hline $\mathrm{Hg}^{2+}$ & 1.02 & -284.7 & -286.0 & -10.9 & -275.1 & 33.6 & -217.8 & -208.2 \\
\hline
\end{tabular}

${ }^{a}$ Ionic radius in tetracoordinated $\mathrm{Be}^{2+}$ complexes and hexacoordinated complexes for the rest of the dications; from Shannon, $1976 .{ }^{32}$

Table 2. Metal Cationic Radii (̊), Metal Partial Charges (in e), and Charge Transfer from $\alpha \mathrm{CD}$ to the Metal Cation (in e) in $[\alpha C D-M]^{2+}$ Complexes

$\begin{array}{cccc}\text { metal cation } & \text { ionic radius } & \text { metal charge (NBO analysis) } & \text { charge transfer } \\ \mathrm{Be}^{2+} & 0.27 & 1.307 & 0.693 \\ \mathrm{Mg}^{2+} & 0.72 & 1.611 & 0.389 \\ \mathrm{Ca}^{2+} & 1.00 & 1.788 & 0.212 \\ \mathrm{Sr}^{2+} & 1.18 & 1.614 & 0.386 \\ \mathrm{Ba}^{2+} & 1.35 & -{ }^{a} & -{ }^{a} \\ \mathrm{Zn}^{2+} & 0.74 & 1.517 & 0.483 \\ \mathrm{Cd}^{2+} & 0.95 & 1.555 & 0.445 \\ \mathrm{Hg}^{2+} & 1.02 & 1.430 & 0.570\end{array}$

${ }^{a}$ Not evaluated.

The metal cation position and distances to ligating $\mathrm{OH}$-groups were allowed to relax and find their optimum values. Resultant energies/free energies are given in Table 1 (last two columns). Comparison between $\Delta E_{\mathrm{el}} / \Delta G$ in the fully and partially optimized complexes reveals significant energy fluctuations upon rigidifying the host system, ranging from $\sim 160 \mathrm{kcal} / \mathrm{mol}$ for the smallest $\mathrm{Be}^{2+}$ cation to $\sim 30 \mathrm{kcal} / \mathrm{mol}$ for the bulkiest $\mathrm{Sr}^{2+}$ and $\mathrm{Ba}^{2+}$ cations. The smaller is the cation, the more substantial are the energy changes inflicted by the bound cation. The calculations demonstrate that the metal affinity of the host molecule (especially toward smaller cations) sharply decreases with increasing its rigidity. However, rigidifying the host system does not alter its selectivity, which is still in favor of smaller and better charge-accepting cations. The same trend in the energies/free energies fluctuations was observed when the flexibility of the host molecule was assessed by an alternative approach: the initial central position of the metal was kept frozen, while the structure of the $\alpha \mathrm{CD}$ was allowed to relax during the optimization process (Table S2).

Another intriguing question arises: Apart from the narrow rim, are there other localities of the host molecule able to accommodate the guest metal species and, if so, with what affinities? In addressing this question, we monitored the effect of varying position of the metal cation inside the $\alpha \mathrm{CD}$ cavity on the free energies of complexation. $\alpha \mathrm{CD}$ complexes of two representatives of the metal series, $\mathrm{Mg}^{2+}$ (small cation with high positive charge density) and $\mathrm{Sr}^{2+}$ (bulkier cation, weaker Louis acid), were modeled and their properties examined. The initial/ starting position of the metal ion was on the narrow rim of the fully optimized $\alpha \mathrm{CD}$, and the metal ion was gradually moved to the lower rim in $1 \AA$ increments either along the cone axis (Figure $3 \mathrm{a}$ ) or tilted to the side wall (Figure $3 \mathrm{~b}$ ). Single point energy evaluations were performed at each step.

Results presented in Table 3 reveal a systematic increase in $\Delta G^{1}$ when moving the metal ions away from the narrow rim of

Table 3. Calculated Gibbs Free Energies in the Gas Phase $\left(\Delta G^{1}\right)$ of the $[\alpha C D-M g]^{2+}$ and $[\alpha C D-S r]^{2+}$ Complex Formation with Metal Ion in Different Positions in the $\alpha \mathrm{CD}$ Cavity

\begin{tabular}{cccccc} 
& \multicolumn{2}{c}{$\Delta G^{1}$ (vertical) } & & \multicolumn{2}{c}{$\Delta G^{1}$ (tilt) } \\
\cline { 2 - 4 } $\begin{array}{c}\text { metal ion } \\
\text { position }(\AA)\end{array}$ & {$[\alpha \mathrm{CD}-\mathrm{Mg}]^{2+}$} & {$[\alpha \mathrm{CD}-\mathrm{Sr}]^{2+}$} & {$[\alpha \mathrm{CD}-\mathrm{Mg}]^{2+}$} & {$[\alpha \mathrm{CD}-\mathrm{Sr}]^{2+}$} \\
0 & -193.4 & -143.0 & -193.4 & -143.0 \\
1 & -154.6 & -117.8 & & -160.0 & -112.7 \\
2 & -89.4 & -57.6 & & -101.6 & -49.5 \\
3 & -39.8 & -9.2 & & -67.9 & 6.2 \\
4 & -16.5 & 21.9 & -69.2 & 19.7 \\
5 & -4.0 & 45.3 & -50.2 & 49.0 \\
\hline
\end{tabular}

the host molecule, rendering these locations less attractive for the guest metal species. Nevertheless, $\Delta G^{1}$ values for $[\alpha \mathrm{CD}-$ $\mathrm{Mg}]^{2+}$ in all positions of the metal ion are negative, implying favorable host-guest interactions despite the relatively high degree of hydrophobicity of the cavity walls. Note that moving the cation away from the narrow rim has a more dramatic effect
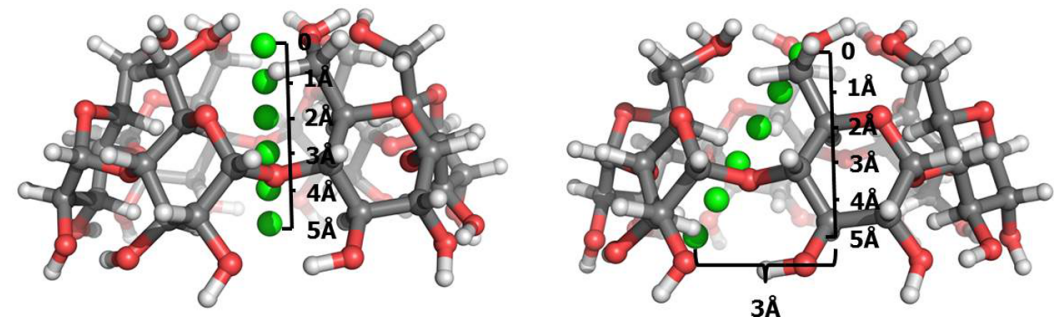

Figure 3. Complexes of $\alpha \mathrm{CD}$ with nonhydrated $\mathrm{Mg}^{2+}$ and $\mathrm{Sr}^{2+}$ ions in different positions in the cavity: (a) vertical and (b) tilt positions. 

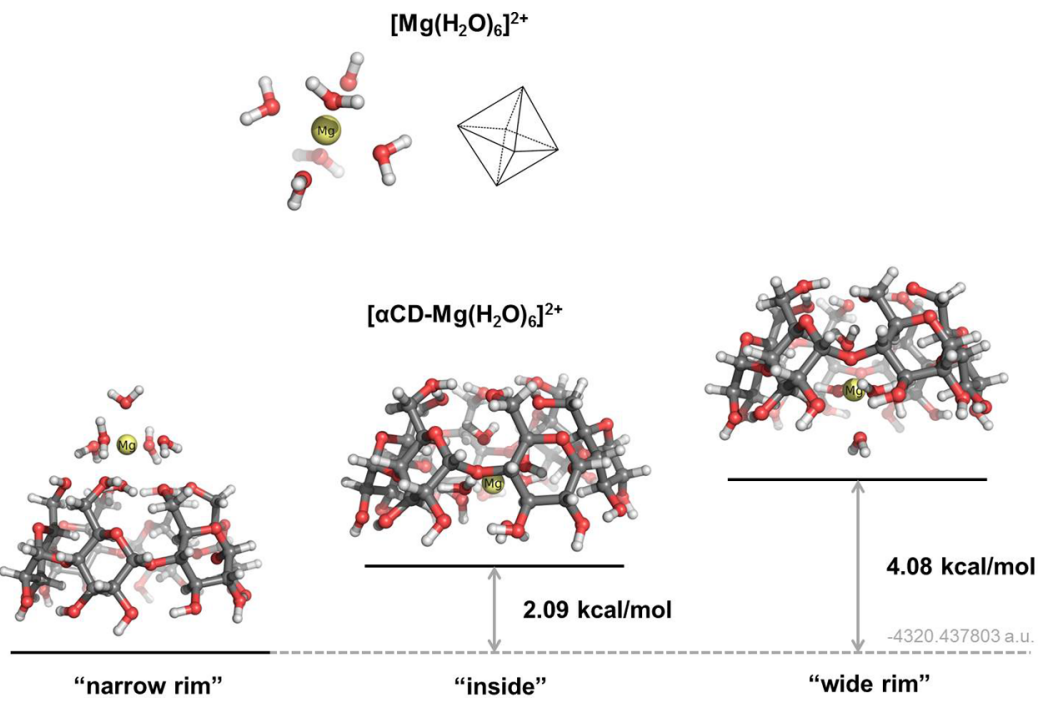

Figure 4. $\mathrm{M} 062 \mathrm{X} / 6-31 \mathrm{G}(\mathrm{d}, \mathrm{p})$ fully optimized structures and relative stabilities of the $\left[\alpha \mathrm{CD}-\mathrm{Mg}\left(\mathrm{H}_{2} \mathrm{O}\right)_{6}\right]^{2+}$ complexes.

on the $\mathrm{Sr}^{2+}$ complexation than $\mathrm{Mg}^{2+}$ complexation, where at longer distances $(>3 \AA)$ the free energy of the former becomes positive making the interactions at these positions unfavorable. This finding is not surprising in view of the weaker ligand affinity of $\mathrm{Sr}^{2+}$ relative to $\mathrm{Mg}^{2+}$, which appears insufficient to maintain attractive interactions with the host molecule at localities far from the narrow belt. Furthermore, sliding the guest $\mathrm{Mg}^{2+}$ cation along the cavity wall ("tilt" configuration) appears thermodynamically more favorable relative to the axial movement (more negative $\Delta G^{1}$ for the former than the latter in Table 3). The opposite is observed for $\mathrm{Sr}^{2+}$ where the vertical configurations were found to be energetically more favorable than their tilted counterparts. This is mostly due to the difference in the coordination number preferences of the two cations: $\mathrm{Mg}^{2+}$, in vertical alignment, is forced to adopt an unfavorable in-plane coordination number of 6 with much longer-than-optimum $\mathrm{Mg}-\mathrm{O}$ bond distances $\left(R_{\mathrm{Mg}-\mathrm{O}}{ }^{\mathrm{Opt}}=2.03\right.$ $\AA$, Figure 2; $R_{\mathrm{Mg}-\mathrm{O}} " 0 "=2.71 \AA$, Figure 3 ), whereas the tilted configuration allows the cation to reduce its coordination number and move closer to only a few oxygen-containing attractors from the cavity walls, thus securing more favorable interactions with its partner molecule. On the other side, $\mathrm{Sr}^{2+}$, with higher propensity toward larger coordination numbers $\left(R_{\mathrm{Sr}-\mathrm{O}}{ }^{\mathrm{Opt}}=2.69 \AA\right.$, Figure 2; $R_{\mathrm{Sr}-\mathrm{O}} " \mathrm{o"}=2.71 \AA$, Figure 3), favors axial (coordination number $=6$ ) configuration better than the tilted one (coordination number $<6$ ).

$\alpha C D$ as a Second-Shell Ligand: $\left[\alpha C D-M g\left(\mathrm{H}_{2} \mathrm{O}\right)_{6}\right]^{2+}$ Complexes. The effect of metal hydration on complexation process was studied by employing supramolecular approach. The group II metals in their +2 oxidation state have a hydration number of 6 (except $\mathrm{Be}^{2+}$ ) with octahedral arrangement of the water ligands (Figure 3). Magnesium hexaaqua complex, $\left[\mathrm{Mg}\left(\mathrm{H}_{2} \mathrm{O}\right)_{6}\right]^{2+}$, was modeled as a representative of the hydrated metal species from the series and taken for further evaluations. The metal binding affinities of different localities of the host cavity were probed. Accordingly, several different types of complexes of hexaaqua magnesium ion with $\alpha \mathrm{CD}$ were modeled where the host $\alpha \mathrm{CD}$ molecule acts as a ligand from the metal's second coordination sphere: $(1)\left[\mathrm{Mg}\left(\mathrm{H}_{2} \mathrm{O}\right)_{6}\right]^{2+}$ ion is located near the narrow rim of the $\alpha \mathrm{CD}$, and only one of the water molecules is located inside the cavity of the $\alpha \mathrm{CD}$ ("narrow rim"); (2) $\left[\mathrm{Mg}\left(\mathrm{H}_{2} \mathrm{O}\right)_{6}\right]^{2+}$ complex is entirely buried inside the cavity ("inside"); and (3) the magnesium ion of the $\left[\mathrm{Mg}\left(\mathrm{H}_{2} \mathrm{O}\right)_{6}\right]^{2+}$ complex is at the level of the wide rim of the $\alpha \mathrm{CD}$, while one of the water molecules is completely outside the cavity of $\alpha \mathrm{CD}$ ("wide rim").

Figure 4 and Table 4 show the overall shape of the three discussed complexes, as well as their relative stability. First,

Table 4. Calculated Gibbs Free Energies in the Gas Phase $\left(\Delta G^{1}\right)$ and in Water Environment $\left(\Delta G^{78}\right)$ (in $\left.\mathrm{kcal} / \mathrm{mol}\right)$ for $\left[\alpha \mathrm{CD}-\mathrm{Mg}\left(\mathrm{H}_{2} \mathrm{O}\right)_{6}\right]^{2+}$ Complex Formation, $\alpha \mathrm{CD}+$ $\left[\mathrm{Mg}\left(\mathrm{H}_{2} \mathrm{O}\right)_{6}\right]^{2+} \rightarrow\left[\alpha \mathrm{CD}-\mathrm{Mg}\left(\mathrm{H}_{2} \mathrm{O}\right)_{6}\right]^{2+}$

\begin{tabular}{lcc} 
c complex & $\Delta G^{1}$ & $\Delta G^{78}$ \\
1 ("narrow rim") & -77.0 & -15.4 \\
2 (“inside") & -74.9 & -5.9 \\
3 (“wide rim") & -72.9 & -6.8 \\
\hline
\end{tabular}

calculations demonstrate that placing the $\alpha \mathrm{CD}$ molecule in the metal's second coordination shell significantly increases the interaction energy, making the process of the host-(hydratedguest) recognition less favorable than that of the respective host-(bare-guest) recognition (less negative interaction free energies in Table 4 than in Table 1). However, the metal binding to the host molecule is still favorable as evidenced by the negative values of $\Delta G^{1}$ and $\Delta G^{78}$ in Table 4 .

Among the three types of $\left[\alpha \mathrm{CD}-\mathrm{Mg}\left(\mathrm{H}_{2} \mathrm{O}\right)_{6}\right]^{2+}$ complexes, the most advantageous is the structure where the $[\mathrm{Mg}$ $\left.\left(\mathrm{H}_{2} \mathrm{O}\right)_{6}\right]^{2+}$ ion is placed near to the narrow rim of the $\alpha \mathrm{CD}$ (lowest $\Delta G$ 's in Table 4). This finding is not surprising in view of the highest negative electron density of the host molecule located in the vicinity of the narrow rim (Figure 5) securing the most favorable interactions with the guest cationic species at that location. The negative $\Delta G$ values obtained for the other complexes ("inside" and "wide rim") imply that these locations are also potential binding sites for the incoming hydrated metal cation, although characterized by lower affinity than the "narrow rim" locality.

\section{CONCLUSIONS}

By employing density functional theory (DFT) calculations combined with continuum dielectric method (CDM) computations, the thermodynamic descriptors $\left(\Delta G^{1}\right.$ and $\left.\Delta G^{78}\right)$ of the 


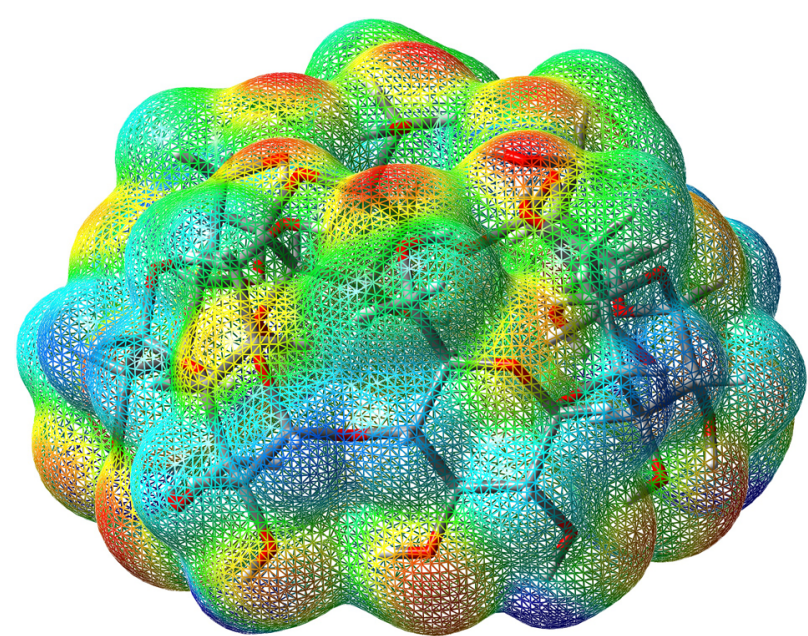

Figure 5. Electron density (isovalue $=0.002$ ), mapped with electrostatic potential (color scheme: red for negative surface map values and blue for the positive ones).

metal binding to $\alpha \mathrm{CD}$ have been evaluated and the interaction between the two binding partners assessed. The metal cation properties (ion radius, electron configuration, coordination number) influence the metal $-\alpha$-cyclodextrin recognition process where the $\alpha \mathrm{CD}$ preferentially binds smaller cations with enhanced charge-accepting abilities. The trimmed with $\mathrm{OH}$ groups narrow rim exhibits greatest affinity for the "naked" metal cations. Furthermore, the calculations indicate that the flexibility of the host ligand is another key factor controlling the energetics of the metal $-\alpha \mathrm{CD}$ complex formation: flexible host structures able to adapt to the geometrical and physicochemical requirements of the guest cation secure very favorable interaction energies.

The solvation effects significantly attenuate the free energy gains in the gas phase and render some reactions (with bulkier metal cations) unfavorable in aqueous medium. Our results demonstrate that placing the $\alpha \mathrm{CD}$ molecule in the metal's second coordination shell significantly increases the interaction energy, making the process of host-(hydrated-guest) recognition less favorable than that of the respective host-(bareguest) recognition, although the metal binding to the host molecule is still favorable as evidenced by the negative $\Delta G^{1}$ and $\Delta G^{78}$ values. By modeling the $\alpha \mathrm{CD}-$ metal cation host-guest interactions, some shortfalls in our knowledge have been overcome: the results obtained shed light on the intimate mechanism of the metal binding to $\alpha \mathrm{CD}$ and disclose the key factors governing the process.

The quest for a deeper understanding of the processes of metal binding and selectivity in cyclodextrins is far from over. Several outstanding questions, not answered in the present study, still remain: (i) What is the role of explicit hydration/ partial hydration of the metal cation in the process of metalcyclodextrin recognition? (ii) What are the kinetic determinants of the metal binding and selectivity in cyclodextrins? (iii) What are the metal ligating properties of higher members of the cyclodextrin family, such as $\beta$ - and $\gamma$-cyclodextrins, and how do their metal affinity and selectivity compare with those of the $\alpha$ counterpart?

\section{ASSOCIATED CONTENT}

\section{S Supporting Information}

The Supporting Information is available free of charge on the ACS Publications website at DOI: 10.1021/acs.inorgchem.6b02564.

Data on the performance of the M062X/6-31G(d,p) method in the calculation of mean metal-oxygen bond distances in complexes with ligands resembling $\alpha \mathrm{CD}$ and energies/free energies of metal complex formation by employing different optimization schemes (PDF)

\section{AUTHOR INFORMATION}

\section{Corresponding Author}

*Phone: (+359 2) 8161 323. E-mail: t.dudev@chem.uni-sofia. bg.

\section{ORCID}

Todor Dudev: 0000-0002-8186-2141

Notes

The authors declare no competing financial interest.

\section{ACKNOWLEDGMENTS}

This work was supported by the Horizon 2020 program of the European Commission (project Materials Networking) and the Bulgarian Scientific Fund under Project "MADARA" at IOCCP-BAS (RNF01/0110, contract no. DO02-52/2008).

\section{REFERENCES}

(1) Villiers, A. Sur la fermentation de la fécule par l'action du ferment butyriqué. C. R. Hebd. Seances Acad. Sci. 1891, 112, 536-538.

(2) Szejtli, J. Introduction and General Overview of Cyclodextrin Chemistry. Chem. Rev. 1998, 98, 1743-1754.

(3) Crini, G. Review: A History of Cyclodextrins. Chem. Rev. 2014, 114, 10940-10975.

(4) Chen, G.; Jiang, M. Cyclodextrin-based inclusion complexation bridging supramolecular chemistry and macromolecular self-assembly. Chem. Soc. Rev. 2011, 40, 2254-2266.

(5) Connors, K. A. The Stability of Cyclodextrin Complexes in Solution. Chem. Rev. 1997, 97, 1325-1358.

(6) Loftsson, T.; Brewster, M. E. Pharmaceutical Applications of Cyclodextrins. 1. Drug Solubilization and Stabilization. J. Pharm. Sci. 1996, 85, 1017-1025.

(7) Davis, M. E.; Brewster, M. E. Cyclodextrin-based pharmaceutics: past, present and future. Nat. Rev. Drug Discovery 2004, 3, 1023-1035.

(8) Astray, G.; Gonzalez-Barreiro, C.; Mejuto, J. C.; Rial-Otero, R.; Simal-Garndara, J. A review on the use of cyclodextrins in foods. Food Hydrocolloids 2009, 23, 1631-1640.

(9) Breslow, R.; Dong, S. D. Biomimetic Reactions Catalyzed by Cyclodextrins and Their Derivatives. Chem. Rev. 1998, 98, 1997-2011.

(10) Del Valle, E. M. M. Cyclodextrins and their uses: a review. Process Biochem. 2004, 39, 1033-1046.

(11) Hedges, A. R. Industrial applications of cyclodextrins. Chem. Rev. 1998, 98, 2035-2044.

(12) Buschmann, H.-J.; Schollmeyer, E. Applications of cyclodextrins in cosmetic products: a review. J. Cosmet. Sci. 2002, 53, 185-191.

(13) Cyclodextrins and Their Complexes: Chemistry, Analytical Methods, Applications; Dodziuk, H., Ed.; Wiley-VCH Verlag: Weinheim, 2006.

(14) Szejtli, J. Utilization of cyclodextrins in industrial products and processes. J. Mater. Chem. 1997, 7, 575-587.

(15) Frömming, K.-H.; Szejtli, J. Cyclodextrins in Pharmacy; Kluwer Academic Publishers: The Netherlands, 1994.

(16) Mamad-Hemouch, H.; Ramoul, H.; Taha, M. A.; Bacri, L.; Huin, C.; Przybylski, C.; Oukhaled, A.; Thiebot, B.; Patriarche, G.; Jarroux, N.; Pelta, J. Biomimetic nanotubes based on cyclodextrins for ionchannel applications. Nano Lett. 2015, 15, 7748-7754. 
(17) Nageswar, Y. V. D.; Murthy, S. N.; Madhav, B.; Shankar, J. Recent Advances in Biomimetic Synthesis Involving Cyclodextrins. In Advances in Biomimetics; Cavrak, M., Ed.; InTech, 2011.

(18) Tabusni, I.; Kuroda, Y. Cyclodextrins and Cyclophanes as Enzyme Models. Advances in Catalysis; Academic Press Inc.: New York, 1983; Vol. 32.

(19) Cai, Y.; Tarr, M. A.; Xu, G.; Yalcin, T.; Cole, R. B. Dication Induced Stabilization of Gas-phase Ternary Beta-Cyclodextrin Inclusion Complexes Observed by Electrospray Mass Spectrometry. J. Am. Soc. Mass Spectrom. 2003, 14, 449-459.

(20) Frański, R.; Gierczyk, B.; Schroeder, G.; Beck, S.; Springer, A.; Linscheid, M. Mass spectrometric decompositions of cationized $\beta$ cyclodextrin. Carbohydr. Res. 2005, 340, 1567-1572.

(21) Zhang, Y.; Xu, W. The aldol condensation catalyzed by metal(II)-b-cyclodextrin complexes. Synth. Commun. 1989, 19, 12911296.

(22) Kurkov, S.; Loftsson, T. Cyclodextrins. Int. J. Pharm. 2013, 453, $167-180$.

(23) He, Z.; Wang, Z.; Zhang, H.; Pan, X.; Su, W.; Liang, D.; Wu, C. Doxycycline and hydroxypropyl- $\beta$-cyclodextrin complex in poloxamer thermal sensitive hydrogel for ophthalmic delivery. Acta Pharm. Sin. B 2011, 1, 254-260.

(24) Stachowicz, A.; Styrcz, A.; Korchowiec, J.; Modaressi, A.; Rogalski, M. DFT studies of cation binding by b-cyclodextrin. Theor. Chem. Acc. 2011, 130, 939-953.

(25) Zhao, Y.; Truhlar, D. G. The M06 suite of density functionals for main group thermochemistry, thermochemical kinetics, noncovalent interactions, excited states, and transition elements: Two new functionals and systematic testing of four M06-class functionals and 12 other functionals. Theor. Chem. Acc. 2006, 120, 215-241.

(26) Gaussian 09, revision D.01; Gaussian, Inc.: Wallingford, CT, 2009.

(27) Yang, L.; Su, Y.; Xu, Y.; Wang, Z.; Guo, Z.; Weng, S.; Yan, C.; Zhang, S.; Wu, J. Interactions between Metal Ions and Carbohydrates. Coordination Behavior of Neutral Erythritol to $\mathrm{Ca}(\mathrm{II})$ and Lanthanide Ions. Inorg. Chem. 2003, 42, 5844-5856.

(28) Bugg, C. E. Calcium Binding to Carbohydrates. Crystal Structure of a Hydrated Calcium Bromide Complex of Lactose. J. Am. Chem. Soc. 1973, 95, 908-913.

(29) Zheng, J.; Alecu, I. M.; Lynch, B. J.; Zhao, Y.; Truhlar, D. G. Database of Frequency Scale Factors for Electronic Model Chemistries; https://comp.chem.umn.edu/freqscale/freq_scale_v1.1. htm, 2010.

(30) Miertuš, S.; Scrocco, E.; Tomasi, J. Electrostatic Interaction of a Solute with a Continuum. A Direct Utilization of ab initio Molecular Potentials for the Prevision of Solvent Effects. Chem. Phys. 1981, 55, $117-129$.

(31) PyMOL v. 1.7.6.6; Schrödinger, LLC.

(32) Shannon, R. D. Revised Effective Ionic Radii and Systematic Studies of Interatomic Distances in Halides and Chalcogenides. Acta Crystallogr., Sect. A: Cryst. Phys., Diffr., Theor. Gen. Crystallogr. 1976, A32, 751-767.

(33) Yucheng, J.; Shiyang, G.; Shuping, X.; Mancheng, H.; Jianji, W.; Yan, L.; Kelei, Z. The enthalpy and entropy interaction parameters of cesium chloride with saccharides (D-glucose, $\mathrm{D}$-fructose and sucrose) in water at $298.15 \mathrm{~K}$. Thermochim. Acta 2003, 400, 37-42.

(34) Saladini, M.; Menabue, L.; Ferrari, E. Sugar complexes with metal ${ }^{2+}$ ions: thermodynamic parameters of associations of $\mathrm{Ca}^{2+}, \mathrm{Mg}^{2+}$ and $\mathrm{Zn}^{2+}$ with galactaric acid. Carbohydr. Res. 2001, 336, 55-61.

(35) Angyal, S. J. Complexes of metal cations with carbohydrates in solution. Adv. carbohydr. Chem. and biochem. 1989, 47, 1-43. 